\title{
The Corrosion Protection Behaviour of Zinc Rich Epoxy Paint in 3\% NaCl Solution
}

\author{
Nadia Hammouda ${ }^{1}$, Hacène Chadli $^{2}$, Gildas Guillemot ${ }^{3}$, Kamel Belmokre ${ }^{1}$ \\ ${ }^{1}$ Laboratoire d'Anticorrosion Matériaux Environnement, Université du 20 Août 1955, Skikda, Algérie \\ ${ }^{2}$ Laboratoire de Métallurgie et Génie des Matériaux, Université de Badji Mokhtar, Annaba, Algérie \\ ${ }^{3}$ Laboratoire de Métallurgie Physique et Génie des Matériaux, Ecole Nationale \\ Supérieure d'Arts et Métiers de Lille, Lille Cedex, France \\ E-mail: hammoudanad@yahoo.fr \\ Received January 16, 2011; revised March 16, 2011; accepted March 25, 2011
}

\begin{abstract}
Electrochemical impedance spectroscopy (EIS) in the $100 \mathrm{kHz}-10 \mathrm{mHz}$ frequency range was employed as the main electrochemical technique to study the corrosion protection behaviour of zinc rich epoxy paint in $3 \% \mathrm{NaCl}$ solution. The EIS results obtained at the open-circuit corrosion potential have been interpreted using a model involving the impedance of particle to particle contact to account for the increasing resistance between zinc particles with immersion period, in addition to the impedance due to the zinc surface oxide layer and the electrical resistivity of the binder. Galvanic current and $d c$ potential measurements allowed us to conclude that the cathodic protection effect of the paint takes some time to be achieved. The loss of cathodic protection is due to a double effect: the decrease of the $\mathrm{Zn} / \mathrm{Fe}$ area ratio due to $\mathrm{Zn}$ corrosion and the loss of electric contact between $\mathrm{Zn}$ to $\mathrm{Zn}$ particles. Even when the cathodic protection effect by $\mathrm{Zn}$ dust become weak, the substrate steel is still protected against corrosion due to the barrier nature of the ZRP film reinforced by Zn.
\end{abstract}

Keywords: Zinc-Rich Epoxy Paints, Cathodic Protection, Electrochemical Impedance Spectroscopy, Corrosion Mechanisms

\section{Introduction}

The application of zinc-rich primers on ferrous substrates is a very efficient method of anticorrosion protection. They are used in many aggressive media: sea water, marine and industrial environments. It is a common fact that in order to achieve a long-life coating system, a zinc primer needs to be applied as the first coat. For solvent-based zinc-rich paints (ZRPs), it seems to be established that, at least at the beginning of immersion, zinc particles provide a cathodic protection of the steel substrate $[1,2]$. Then, a long term protection develops due to the formation of zinc corrosion products, reinforcing the barrier effect of the paint $[1,3]$.

The metallic zinc content in the dry film is a very important parameter to be emphasized in the technical specifications of zinc-rich paints. However, as observed by Lindquist et al., [4] this parameter is not the only factor determining the performance of this kind of paint. For exemple, Fragata [5] Del Amo [6] and Pereira [7] verified that the chemical nature of the binder and the zinc particle size are also very important.

The zinc dust (spherical or lamellar shape, or a combination of both) is dispersed in an inorganic (usually orthosilicates) or organic binder (usually epoxies) [8]. These particles must be in electrical contact between themselves and the metallic substrate in order to ensure a well-established electrical conduction within the coating. In such conditions of percolation, a galvanic coupling is created between zinc and the substrate (steel) which is nobler than the zinc. Then, zinc can preferentially dissolve, acting as a sacrificial pigment, and allowing a cathodic protection of the substrate. Many studies [9-19] exist in literature and relate the protection mechanisms and degradation processes of such coatings.

Physico-chemical properties and corrosion resistance of solvent-based zinc-rich paints ZRPs strongly depend on pigment volume concentration (PVC), shape and size of zinc dust $[19,20]$. In common liquid ZRP, zinc is usually introduced as spherical pigments with a mean diameter ranging from 5 to $10 \mu \mathrm{m}$. To ensure good electrical contacts between zinc pigments and the steel sub- 
strate, a high pigment concentration is required (usually above $60 \%$ by volume in solvent-based zinc-rich paints ZRPs) [19]. A major drawback of classic solvent-based paint is the emission of volatile organic compounds (VOC), which contribute to atmospheric pollution. Since the $1970 \mathrm{~s}$, powder coatings are often preferred, because they are composed of dry thermosetting powders (without organic solvent) and more environmental abiding.

The aim of this work was to study the protective mechanisms of a single coat solvent-based zinc-rich paints ZRPs. Primer coating panels were applied on sandblasting steel and were studied when immersed in artificial $3 \% \mathrm{NaCl}$ solution. The electrochemical behaviour was studied using electrochemical impedance spectroscopy (EIS) and by monitoring the free corrosion potential versus time. Raman spectroscopy was employed to explore the oxidative state of zinc-rich paints after immersion and to detect the zinc corrosion products, S.E.M. observations have also been employed to illustrate the nonhomogeneity of our paints.

The main objective is to propose a model of EIS results accounting for the zinc particles distribution and mechanisms of water entrance within the coating.

\section{Experimental Part}

\subsection{Sample Material and Preparation}

The metallic substrate was A283C steel (according to NF10027 standard) in conformity with the norm API (American Petroleum Industry), used in the storage reservoirs of the Algerian crude oil, the chemical composition of the tested steel is given in Table 1. Before coating application, the metallic substrate was sandblasted to Sa 2.5 (Swedish Standard SIS 0559 00/67) (roughness Ra $6.2 \mu \mathrm{m}$ ) or polished with emery paper up to $\mathrm{G} 400$. Commercial epoxy-ZRPs were immediately applied onto steel panels using a brush or a roller (Figure 1). Once cured, the samples were stocked in a desiccator until the moment of testing. The coating thickness was measured using an Elcometer gauge and was found around $80 \mu \mathrm{m}$ for all panels, the composition of the coating is proprietary information.

Coated panels were cut out $(100 \mathrm{~cm} \times 60 \mathrm{~cm} \times 4 \mathrm{~cm})$ and an electrical wire was added in order to allow electrochemical measurements. With the aim to achieve the electrochemical measures in the best conditions it has been suited that the areas of about $15 \mathrm{~cm}^{2}$ exposed to the electrolytic solution were sufficient. It seemed necessary to use a surface of paint relatively big in contact with electrolytic solution in order to compensate the insulating role of the sample as the thickness of the film grows. Mansfeld reports in a technical document [21] a study of
Table 1. Chemical composition of A283C steel (\% in weight).

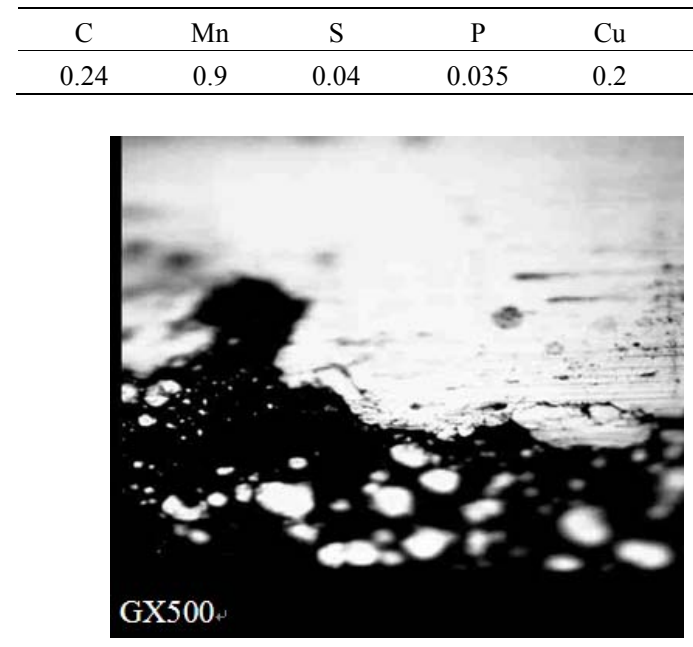

(a)

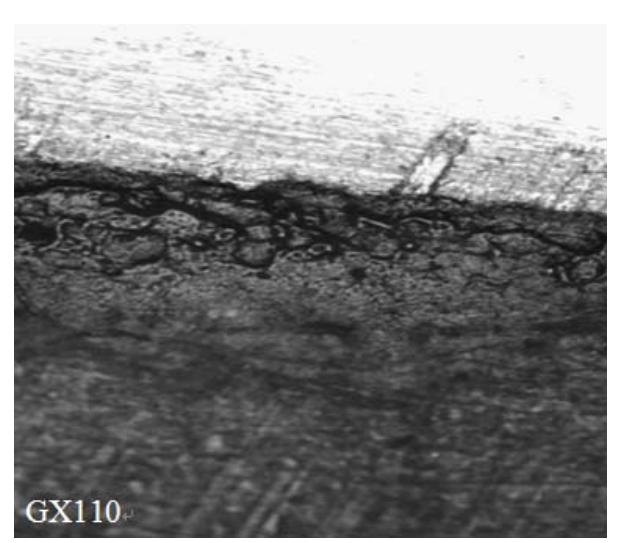

(b)

Figure 1. Cross-section of the studied ZRP. (a) Prior to exposition. The observed white particles are due to the spherical zinc particles. (b) After 360 days of immersion in $\mathbf{~ N a C l}$ $3 \%$. Substrate steel is seen as the white region at the top of micrography.

Kendig and Scully suggesting the use of samples covered with a ratio area/thickness of the coating of at least $10^{4}$ to assure satisfactory electrochemical measurement.

Samples were exposed under open circuit potential conditions in $\mathrm{NaCl}$ aqueous solution normally aired and none agitated whose concentration is $30 \mathrm{~g} / 1$ for electrochemical impedance.

\subsection{Electrochemical Impedance Spectroscopy Measurements}

The Electrochemical Impedance Spectroscopy (EIS) measurement is carried out in a $3 \% \mathrm{NaCl}$ solution, using a potentiostat/galvanostat EG\&G A273. A frequency response analyser Solartron FRA 1260 connected to an 
electrochemical interface Solartron SI 1287 was used to perform EIS measurements. A filter (Kemo VBF 8) was also employed to improve the signal to noise ratio. The frequency domain covered was $100 \mathrm{kHz}$ to $10 \mathrm{mHz}$ with the frequency values spaced logarithmically (five per decade). The width of the sinusoidal voltage signal applied to the system was $10 \mathrm{mV}$. All the measurements were performed at the open circuit potential and at different immersion times. The electrolyte was confined in a glass tube which was fixed to the painted surface by an $\mathrm{O}$-shaped ring. The total tested area was $15 \mathrm{~cm}^{2}$. Platinum gauze of large area was used as a counter electrode. All the potentials in the current article are referred to saturated calomel electrode (SCE). During the intervals between EIS measurements, the painted specimen was kept in the electrolyte cell without reference electrode. The cell design for EIS measurement was described in detail in a previous work [22].

\subsection{Characterization of Wash Primer Coatings}

\subsubsection{FTIR Analysis}

The FTIR spectra of zinc rich epoxy paint were taken with SHIMATZU 8000 série + FTIR Spectrometer using ATR attachment in the range $4000-450 \mathrm{~cm}^{-1}$.

\subsubsection{Micro-Raman Spectroscopy}

Cross sections of the zinc-rich epoxy paint were polished and analyzed ex situ by micro-Raman spectroscopy after immersion. Fresh polishing with $1 \mu \mathrm{m}$ diamond paste was performed just before Raman analysis. Figure 2 shows cross-section obtained by scanning electron microscopy of the ZRP. Only zinc particles (spherical) are observable. This figure shows that the distribution of the spherical pigments is quite inhomogeneous while zinc plates are uniformly distributed. Raman spectrophotometer (Labram from Jobin Yvon with an optical microscope from Horiba) was equipped with a HeNe laser $(632.81 \mathrm{~nm})$; the output power was $0.97 \mathrm{~mW}$ at the sample. A confocal hole set at $200 \mu \mathrm{m}$ allowed an analyzed depth lower than $10 \mu \mathrm{m}$ on transparent products. A 80 ULWD objective from Olympus was used to select the analyzed area. Raman spectra were only acquired on spherical zinc particle frontier.

\section{Results and Discussion}

\subsection{Electrochemical Properties of Sandblasted Steel (Sa $2 \frac{1}{2}$ )}

To the analysis of the curves (Figure 3), we note a continuous deterioration of the sandblasted steel to Sa 2.5

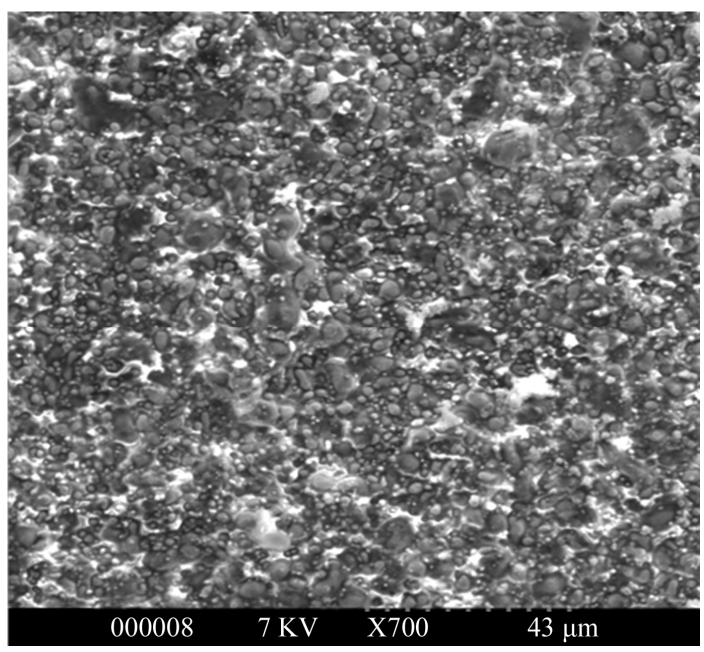

Figure 2. Cross section SEM micrography of the coating wherespherical zinc particle is visible.



Figure 3. Evolution of Nyquist diagrams as a function of immersion time in $3 \% \mathrm{NaCl}$ solution for the sandblasted steel (Sa 2.5).

provoking a change in the state of the metallic surface. It can for example, to cover of corrosion products, weakly adhesive which provoke a stability of the free corrosion potential, the value was around $-0.684 \mathrm{~V} / \mathrm{SCE}$. The diagrams of Nyquist determined to different time of immersion, in the $3 \% \mathrm{NaCl}$ solution normally aired and non agitated are represented on the Figure 3, the values of the different parameters are gathered in the Table 2.

The values of the electrolyte resistance $R_{e}$ are very weak, of the order of $14 \Omega \cdot \mathrm{cm}^{2}$, what shows that the middle is very conductive.

To the analysis of the impedance diagrams, since the first hours of immersion of the metallic substrate, we register a rapid evolution of the charge transfer resistance $\mathrm{R}_{\mathrm{ct}}$ of the sandblasted steel, we note that at the beginning of the immersion the value of the charge transfer resistance $R_{c t}$ only makes increase until to the fourth days of 
Table 2. Parameters values extracted from the fitting procedure.

\begin{tabular}{cccc}
\hline Time (days) & $\mathrm{R}_{\mathrm{e}}\left(\Omega \cdot \mathrm{cm}^{2}\right)$ & $\mathrm{R}_{\mathrm{ct}}\left(\mathrm{K} \Omega \cdot \mathrm{cm}^{2}\right)$ & $\mathrm{C}_{\mathrm{dl}}\left(\mathrm{mF} / \mathrm{cm}^{2}\right)$ \\
\hline $0 \mathrm{~h}$ & 17.97 & 1.044 & 3.810 \\
2 & 13.53 & 3.804 & 4.183 \\
4 & 13.14 & 3.532 & 4.505 \\
7 & 13.77 & 2.201 & 2.892 \\
8 & 14.53 & 4.460 & 3.568 \\
9 & 14.51 & 5.877 & 2.707 \\
11 & 13.65 & 1.706 & 2.331 \\
14 & 14.67 & 2.991 & 2.218 \\
15 & 14.95 & 5.532 & 2.876 \\
18 & 14.28 & 2.597 & 2.450 \\
22 & 16.02 & 2.546 & 2.500 \\
\hline
\end{tabular}

immersion (96 hours), it means that the process governing the kinetics is under control of load transfer. According to the Figure 4 we notes that the charge transfer resistance $\mathrm{R}_{\mathrm{ct}}$ evolves cyclically with time of immersion (growth then decrease) this state of fact to been signalled already by certain author [23,24].

The tracing of the double layer capacitance $\mathrm{C}_{\mathrm{dl}}$ curve as a function of exposure time from the values arranged in the Figure 4, show an increase of the capacity of double layer $\mathrm{C}_{\mathrm{dl}}$ since the first hours of exposure. This growth is more or less important (3.810 to $4.505 \mathrm{mF} \cdot \mathrm{cm}^{-2}$ ) translating the deterioration of steel thus, but beyond the seventh day (168 hours) of immersion it decreases suddenly $\left(2.892 \mathrm{mF} \cdot \mathrm{cm}^{-2}\right)$, we think that the slowing of the decrease of the double layer capacitance $\mathrm{C}_{\mathrm{dl}}$ would be due to the formation of corrosion products (Figure 4) forming a film more or less adhesive to the substrat playing the role of a gate, beyond 216 hours the capacity of double layer fluctuates weakly that we can consider like steady.

This situation has already been met, at the time of our survey with the different states of naked surface. This phenomenon observed by Duprat [25], has been assigned to the porous nature of corrosion products formed at the free corrosion potential and present at the metallic interface (Figure 5).

The model of equivalent circuit proposed and presented in Figure 6 could be used to represent the electrochemical behaviour of our samples after immersion in $3 \% \mathrm{NaCl}$ solution, in this circuit $\mathrm{R}_{\mathrm{e}}$ is the resistance of electrolyte $\left(\Omega \cdot \mathrm{cm}^{2}\right), \mathrm{R}_{\mathrm{ct}}$ the charge transfer resistance $\left(\Omega . \mathrm{cm}^{2}\right) \mathrm{C}_{\mathrm{dl}}$ the double layer capacitance $\left(\mathrm{F} \cdot \mathrm{cm}^{-2}\right)$.

\subsection{EIS Behavior of Zinc Rich Epoxy Paint}

Zinc-rich primers can only protect the steel cathodically when the zinc particles in the primer have electric contact to the steel substrate. Only the zinc particles in direct contact with the steel substrate, or connected through

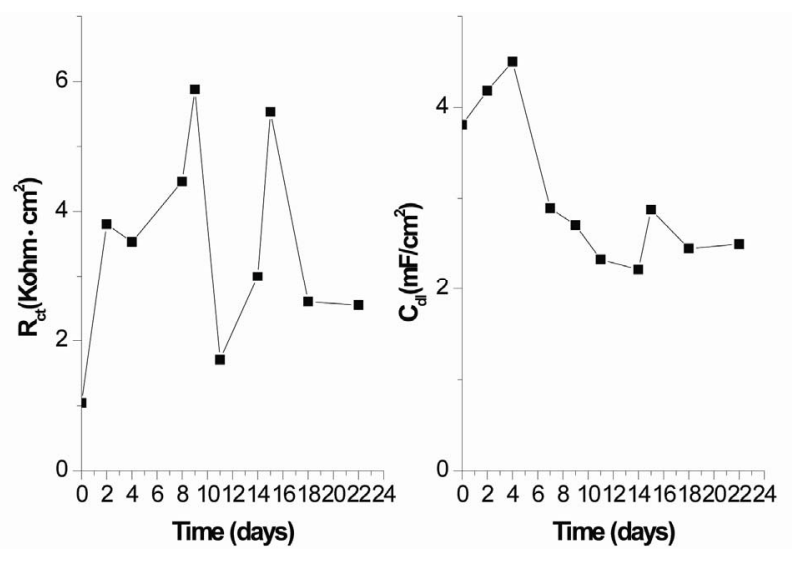

Figure 4. Variation of $R_{c t}$ and $C_{d l}$ with time of exposure.

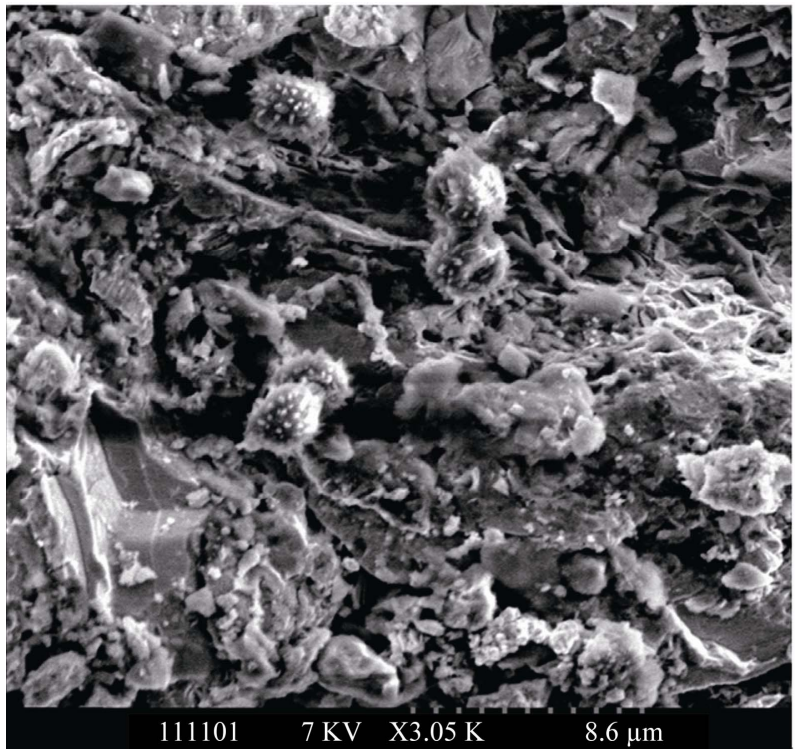

Figure 5. Cross section SEM micrograph on sandblasted steel (Sa 2.5).



Figure 6. Equivalent circuit used to model sandblasted steel (Sa 2.5) during immersion in $3 \% \mathrm{NaCl}$ solution. 
other zinc particles, will contribute to the cathodic protection. It is therefore necessary to have a large amount of zinc dust in the coating.

The potential of ZRP is approximately $-1.160 \mathrm{~V} / \mathrm{SCE}$, while the steel substrate used here has a potential of approximately $-0.65 \mathrm{~V} / \mathrm{SCE}$. The measured potentials are mixed potentials between the steel substrate and the "active" zinc-pigments, and will depend on the area ratio between the two. If only few zinc-pigments are active, the anode area will be small, and the potential will be close to that of the steel. On the other hand, if the area of active zinc particles is large, the potential will be close to that of zinc.

The Nyquist impedance diagrams for the ZRP coated panels obtained in the aerated $3 \% \mathrm{NaCl}$ solution as a function of immersion time are shown in Figure 7(a). Two time constants (two loops) were clearly defined at the beginning of the exposure, that become more and more distinct as the immersion time increases, which corresponds well with the model shown in Figure 10 one in the high frequency range (Figure 7(b)) which is related to the coating properties followed by a second one at lower frequencies which is related to the corrosion process $[26,27]$. At high frequencies, the impedance reduces to one or two semicircles with diameters of charge transfer resistance and pore resistance. At lower frequencies, a Warburg impedance develops on the Nyquist plot by a straight line superimposed at $45^{\circ}$ to both axes, which shows a shielding effect on mass transport of reactants and products. The shape of the impedance plot suggests that the ZRP corrosion changes from charge transfer control process to diffusion control process during time of immersion.

By considering the morphology and the EIS of the ZRP, the impedance first decreased for few days showing the zinc particles activation before an increase related to the zinc corrosion products formation.

The fitting of EIS data was performed by Zview software (Scribners Associates, USA) using different electrical equivalent circuits which include two time constants $[28,29]$.

Another difference with previous studies on ZRPs was found in the visual observation of panels during immersion. Usually, zinc corrosion products are clearly observed as white scale at the ZRP panel surfaces [30] (Figure 8(a)). These new products would be maintained within the coating at the neighbourhood of the corroded zinc particles. Moreover, they could also contribute to the isolation of zinc particles as a protective barrier which reduces the corrosion rate of zinc and the coating porosity. Figure 8(b) shows the visual appearance of zinc rich epoxy paint coated panel after 180 days (six months) of immersion where the whiteness related to the zinc corrosion products was not observed. It means that

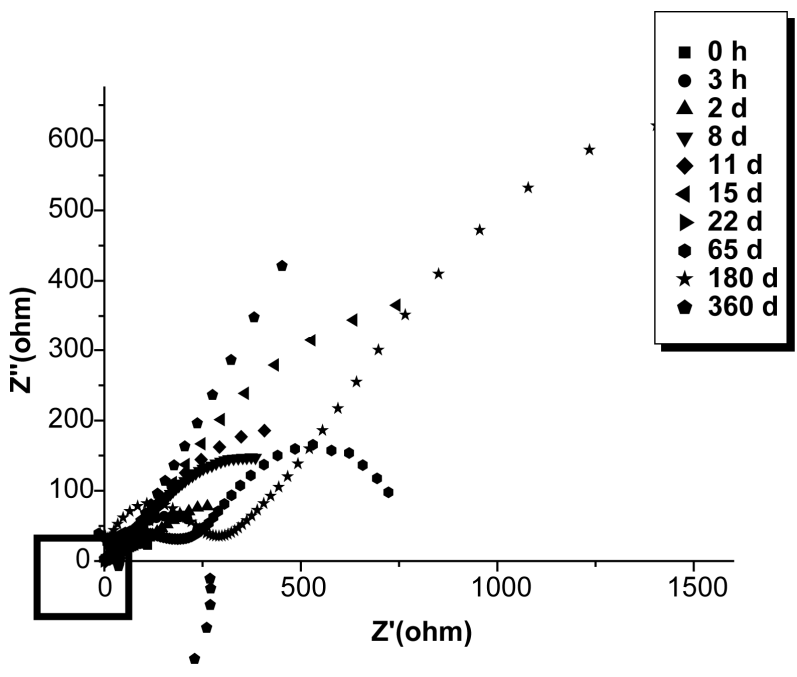

(a)

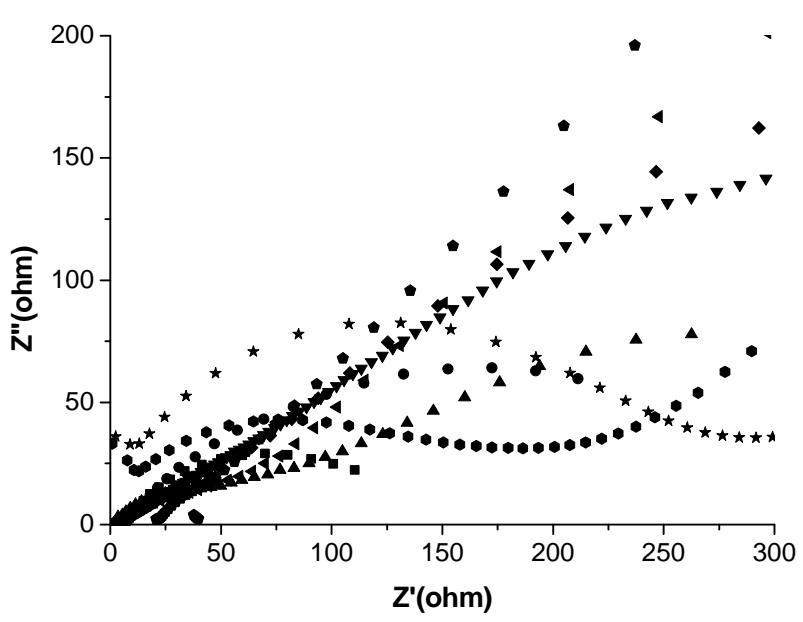

(b)

Figure 7. Electrochemical impedance spectroscopy diagrams for ZRP as a function of immersion time in aerated $3 \%$ NaCl solution.

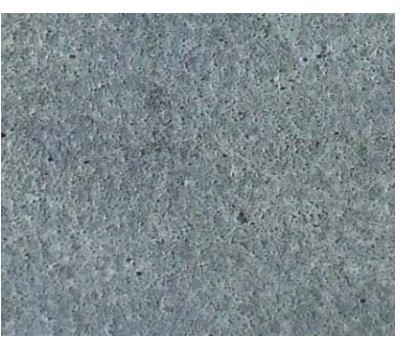

(a)

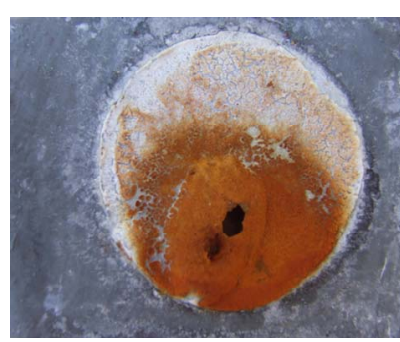

(b)
Figure 8. Visual aspect of zinc rich epoxy paint after six months of immersion in $3 \% \mathrm{NaCl}$ solution.

after zinc corroded, zinc corrosion products were not able to reach the coating/electrolyte interface, the surface appears damaged with the presence of the red rust due to a progressive attack informing on the state of steel sub- 
strat, at this stage of deterioration, the coating lost all its protective properties.

\subsubsection{Ecor Evolution}

According to Abreu et al. [2], the evolution of the free corrosion potential $E_{\text {cor }}$ allows to follow the electrochemical activity of the ZRP. It is believed that the electrochemical processes occurring in such systems are the oxidation of zinc particles $\left(\mathrm{Zn} \rightarrow \mathrm{Zn}^{2+}+2 \grave{e}\right)$ and the reduction of dissolved oxygen $\left(\mathrm{O}_{2}+2 \mathrm{H}_{2} \mathrm{O}+4 \dot{e} \rightarrow\right.$ $4 \mathrm{OH}^{-}$). The authors reported that the $E_{\text {cor }}$ evolution for liquid ZRP coated samples is in close relationship with the ratio of active areas (zinc/steel) and allows to define the cathodic protection (CP) duration which is the period where $E_{\text {cor }}$ remains lower than $-0.86 \mathrm{~V} / \mathrm{SCE}$, a value corresponding to the commonly accepted criterion of a maximum $\mathrm{Fe}^{2+}$ concentration of $10^{-6} \mathrm{M}$. In other words, the increase in this potential corresponds to the decrease of the electroactive zinc area which means the decrease of the cathodic protection intensity. This is generally attributed to the isolation of the zinc particles by the zinc corrosion products in the coating.

Figure 9 shows the $E_{\text {cor }}$ evolution with time of coated steel substrates with Zinc rich epoxy paint. It can be seen that $E_{\text {cor }}$ was cathodic between -1.0 and $-0.8 \mathrm{~V}_{\mathrm{SCE}}$ during the six months of entire immersion, this result could be due to a high zinc particles amount. This shows that the zinc particles in the primers were electrochemically active with a high number of electrical contacts between zinc particles. This high percolation means that zinc pigments improve a good electrical contact which implies that the steel substrate was under a good CP. That means that a higher part of the zinc particles was involved in a percolation process.

However, as the CP duration is due to the activation of zinc particles by the electrolyte penetration, it also means that the zinc dissolution is reduced or that galvanic contact was lost after six months of immersion in $3 \% \mathrm{NaCl}$ solution, some small spots of iron rust are detected on the film surface, indicating that the iron corrosion process started some days before. For our zinc-rich primers, it has been observed that zinc corrosion products precipitate inside the coating, around the zinc particles that originated them, blocking the pores of the coating and therefore increasing its barrier resistance [31]. After the test the latter sample was covered with red rust in a limited area. Probably the primer was very thin there, so that the zinc particles were consumed and the steel started to corrode.

\subsubsection{Equivalent Circuit for the EIS Simulation}

The electrical circuits that are used to simulate the EIS results are shown in Figure 10. By considering the mor-

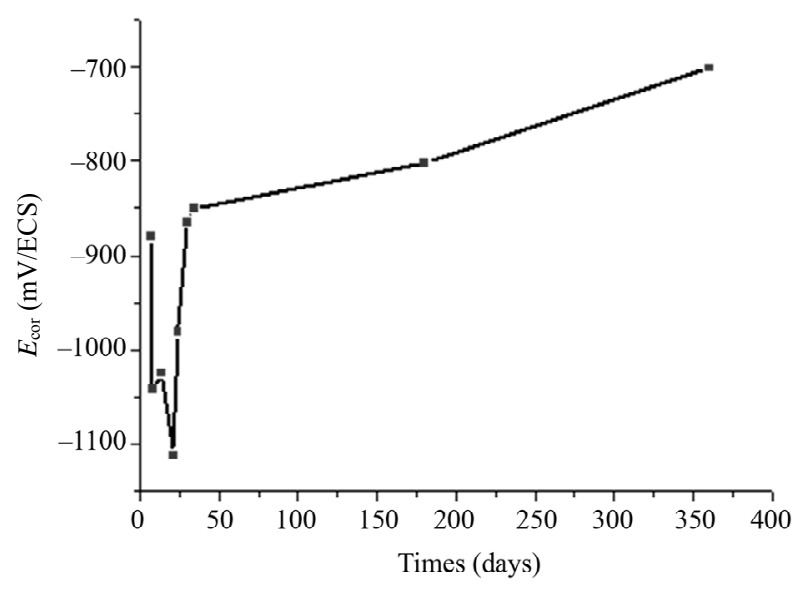

Figure 9. Variations in corrosion potential with time for ZRP exposed in 3\% NaCl solution at ambient temperature.

phology and the EIS of the ZRP, the corrosion process and its equivalent circuit are proposed. At the beginning of the immersion, the model circuit was proposed by the combination of Randles type equivalent circuits for a porous paint film [32] and an intact paint film [33], as shown in Figure 10(a).

In the case of Figure 10(a), the nature of the zinc rich epoxy paint enables the coating to be modelled as an ideal capacitance $C_{f}$ in parallel with the ionic resistance $\mathrm{R}_{\mathrm{f}}$ through the coating. In Figure 10, electrical circuits used to simulate the EIS results.

In the same way the presence of a metal surface without chemical pretreatment together with the iron electrochemical dissolution reaction which involves a single time constant, enables the metal-paint interface to be considered as a resistance (the charge transfer resistance $\mathrm{R}_{\mathrm{ct}}$ ) in parallel with the double layer capacitance $\mathrm{C}_{\mathrm{dl}}$ (the double layer capacitance on quite a rough surface). In this example the suggested model is simple but it is in good agreement with the experimental result (Figure 10(b)). Moreover, after about 180 days of immersion we can observe the appearance of a diffusion tail at the lowest frequencies (Figure 10(c)). In most of the cases, a circuit including diffusion impedance through a layer of finite thickness [2] gave the best agreement between experimental and calculated curves. This circuit describes a degraded coating with a weak charge transfer [34].

\subsection{Micro-Raman Spectroscopy}

In order to understand the behaviour of zinc rich epoxy paint, complementary analyzes were carried out. Raman spectroscopy analyzes were performed after 180 days (6 months) of immersion of the zinc rich epoxy paint. This technique allows to identify locally zinc corrosion products inside the coatings. Representative spectra obtained 


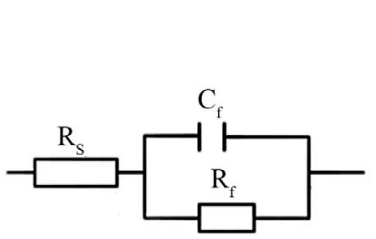

(a)

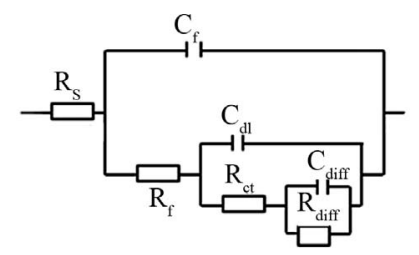

(b)

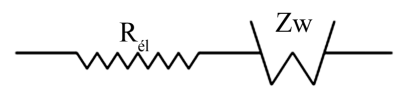

(c)

Figure 10. Electrical circuits used to simulate the EIS results.

for our sample are shown in Figures 11(a) and (b). In Figure 11(a), a characteristic peak was observed at $543 \mathrm{~cm}^{-1}$ which was attributed to a non-stoichiometric oxide $\mathrm{Zn}_{1+\mathrm{x}} \mathrm{O}[35,36]$, which is detected on some particles of zinc to some micrometers of the electrolyte/ coating interface whereas only the metallic zinc is detected on the other particles. This shape of the non-stoichiometric zinc oxide $\mathrm{Zn}_{1+\mathrm{x}} \mathrm{O}$, where zinc ion is in interstitial position had been observed by Tzolov and alli [37].

Other corrosion products were detected inside the coatings and their characteristic wavenumbers (Figure 11(b)). We detected additional peaks at 240.5, 392.2 and $409.7 \mathrm{~cm}^{-1}$ attributed to simonkolleïte $\left[4 \mathrm{Zn}(\mathrm{OH})_{2} \cdot \mathrm{ZnCl}_{2}\right.$. $\left.\mathrm{H}_{2} \mathrm{O}\right]$ a kind of zinc corrosion products, we detected also additional peak at $1340 \mathrm{~cm}^{-1}$. The oxidized forms were first observed at the solution/coating interface and progressed towards the steel substrate as the immersion duration increased.

\subsection{FTIR Spectral Characterization}

The FTIR spectrum of the zinc rich epoxy paint is shown in Figure 12. The peaks around $850 \mathrm{~cm}^{-1}, 1250 \mathrm{~cm}^{-1}$, $1510 \mathrm{~cm}^{-1}, 1600 \mathrm{~cm}^{-1}$ and $1460 \mathrm{~cm}^{-1}$ are due to the resin epoxy. The film is found to be hydrated by the presence of peak at $3400 \mathrm{~cm}^{-1}$ due to O-H absorption band.

From FTIR spectra result, it can be concluded that the synthesised zinc rich epoxy paint was under a conductive form, which is represented in the Figure 13.

\subsection{SEM Analysis}

Cross section S.E.M. micrographs of several ZRP samples exposed to the electrolyte for different time are shown in Figure 14. It was clearly observed that the coating presented zones which did not contain zinc particles. Moreover, it can be seen that the zinc particle shape varied significantly from spherical to elongated forms. Most of the zinc particles were not in direct contact with



Figure 11. Raman spectrum of zinc particles near the interface film/electrolyte after six months of immersion in $\mathbf{3 \%}$ $\mathrm{NaCl}$ solution.

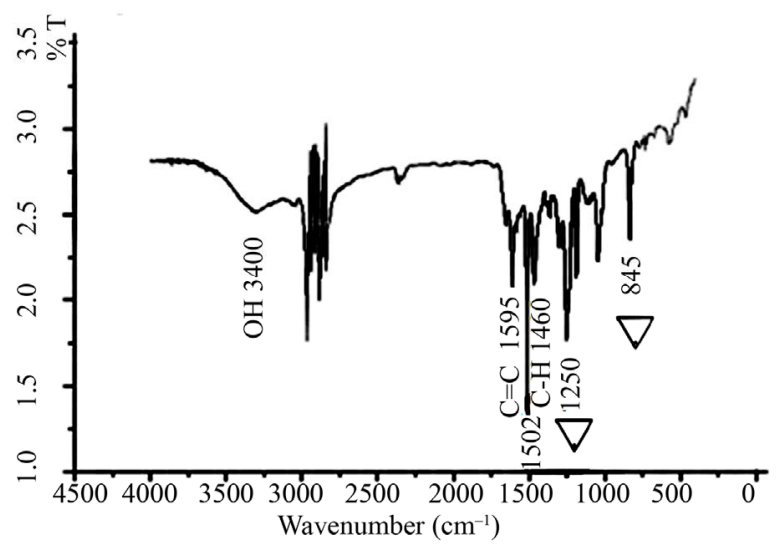

Figure 12. FTIR spectra of zinc rich epoxy paint (ZRP).

the substrate. These observations about the zinc particles distribution were considered to analyse EIS spectra.

Figures 14(a) and (b) represents a testing panel covered with the oxidation products after exposure to $3 \%$ $\mathrm{NaCl}$ solution. The oxidation of zinc in the coating creates the so-called "white corrosion"; the shapes of damage were under Cracks and scaling damage. Sealing of pores in a spherical zinc-pigmented coating. Which is necessary to secure the barrier protection of the substrate. The scheme outlines the possible reactions at the appearance of oxidation zinc products; these products are of alkaline nature and can manifest themselves in the neutralization protection mechanism $[38,39]$.

\section{Conclusions}

Solvent-based zinc-rich paints (ZRPs) was characterised using EIS after immersion in 3\% $\mathrm{NaCl}$ solution. EIS was found to be a useful tool for assessing the protective be- 


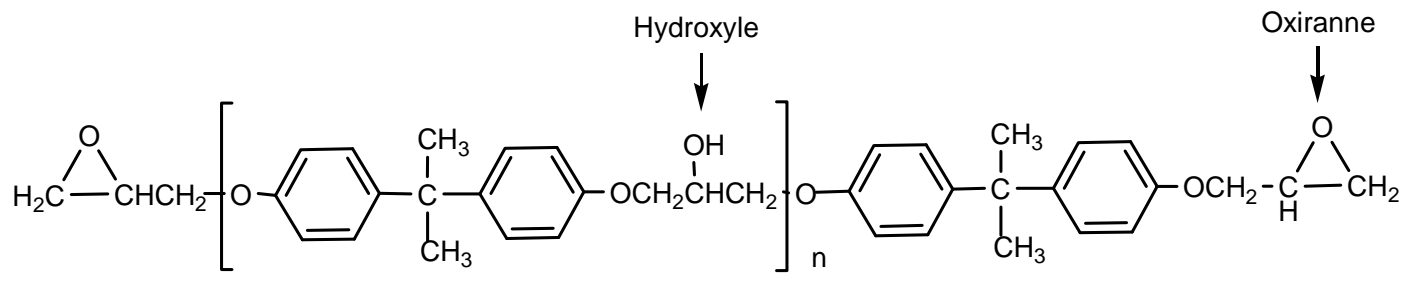

Figure 13. Structural formula of the zinc rich epoxy paint.



(a)

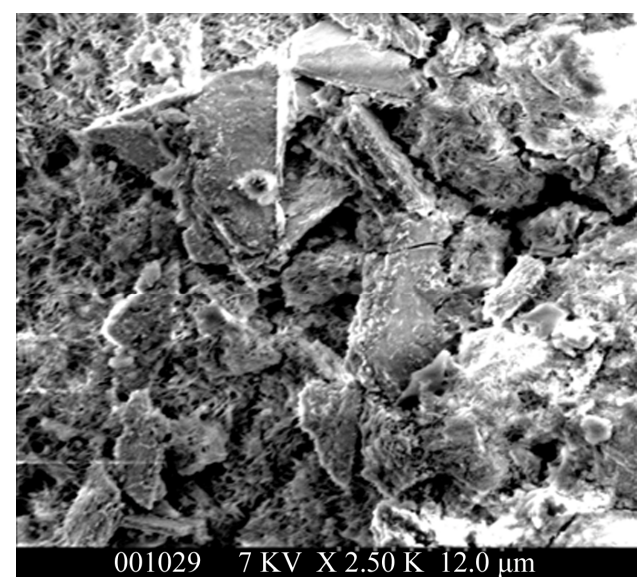

(b)

Figure 14. SEM pictures of zinc rich epoxy paint in $3 \% \mathrm{NaCl}$ solution.

havior of ZRPs organic coatings, after immersion, the EIS diagrams showed clearly two capacitive loops. However, classical equivalent circuits used to monitor coating degradation were unable to provide satisfying fitting results. Results clearly demonstrate that the galvanic protection stage requires good electrical contact among the zinc particles. In samples with a $\mathrm{Zn}$ content higher than $80 \%$, the cathodic protection effect was steel in action after about 180 days of immersion in $3 \% \mathrm{NaCl}$ solution.

The good performance of ZRP coatings during immersion can also be explained by the retention of zinc corrosion products into the coating which allow improving barrier properties. However, it is important to remember that the zinc-rich paint effectiveness does not depend solely on electrochemical factors.

There are other factors such as mechanical properties (cohesion, adhesion to Sa 2.5, flexibility, etc) that are very important. So, the addition of auxiliary pigments should be controlled carefully in order not to impair the film's physical and chemical characteristics. These results highlight that powder zinc-rich coatings are complex systems.

\section{Acknowledgements}

Thanks are due to Sonatrach (Direction Régionale de Skikda, Algeria) for providing ZRP coated panels.

\section{References}

[1] C. H. Hare, "Mechanisms of Corrosion Protection with Surface Treated Wollastonite Pigments," The Journal of Protective Coatings, Vol. 14, 1998. pp. 47-82.

[2] C. M. Abreu, M. Izquierdo, M. Keddam, X. R. Novoa and H. Takenouti, "Electrochemical Behaviour of ZincRich Epoxy Paints in 3\% NaCl Solution," Electrochimica Acta, Vol. 41, No. 15, 1996, pp. 2405-2415. doi:10.1016/0013-4686(96)00021-7

[3] M. Morcillo, R. Barajas, S. Feliu and J. M. Bastidas, "Electrochemical Behavior of Zinc-Rich Coatings", Journal of Materials Science, Vol. 25, No. 5, 1990, pp. 2441-2446. doi:10.1007/BF00638039

[4] S. A. Lindquist, L. Méssaros and L. Svenson, "Aspects of Galvanic Action of Zinc-Rich Paints Electrochemical Investigation of Eight Commercial Primers," Journal of Oil \& Colour Chemists Association, Vol. 68, 1985, p. 10.

[5] F. L. Fragata, M. Sebrão and E. T. Serra, "The Influence of Particle Size and Metallic Zinc Content in the Behaviour of Zinc-Rich Paints," Journal of Coatings Technology, Vol. 6, 1987, p.12.

[6] B. D. Amo and C. A. Giùdice, "Influence of Some Variables on Behaviour of Zinc-Rich Paints Based on Ethyl Silicate and Epoxy Binders," Proceedings 6th International Corrosion Congress, Italy, April 1990, p. 347.

[7] D. Pereira, J. D. Scantlebury, M. G. S. Ferreira and M. C. Almeida, "The Application of Electrochemical Measurements to the Study and Behaviour of Zinc-Rich Coat- 
ings," Corrosion Science, Vol. 30, No. 11, 1990, pp. 1135-1147. doi:10.1016/0010-938X(90)90061-9

[8] Z. W. Wicks, Jr., F. N. Jones and S. P. Pappas, "Organic Coatings: Science and Technology," 2nd Edition, John Wiley and Sons, New York, 1994.

[9] S. Feliu, R. Barajas, J. M. Bastidas and M. Morcillo, "Mechanism of Cathodic Protection of Zinc-Rich Paints by Electrochemical Impedance Spectroscopy," Journal of Coating Technology, Vol. 61, No. 775, 1989, pp. 63-69.

[10] S. Feliu, R. Barajas, J. M. Bastidas and M. Morcillo, "Mechanism of Cathodic Protection of Zinc-Rich Paints by Electrochemical Impedance Spectroscopy. II: Barrier stage," Journal of Coating Technology, Vol. 61, 1989, pp. 71-76.

[11] D. Pereira, J. D. Scantlebury, M. G. S. Ferreira and M. E. Almeida, "The Application of Electrochemical Measurements to the Study and Behaviour of Zinc-Rich Coatings," Corrosion Science, Vol. 30, No. 11, 1990, pp. 1135-1147. doi:10.1016/0010-938X(90)90061-9

[12] R. A. Armas, C. A. Gervasi, A. D. Sarli, S. G. Real and J. R. Vilche, "Zinc-Rich Paints on Steel in Artificial Seawater by Electrochemical Impedance Spectroscopy," Corrosion, Vol. 48, No. 5, 1992, pp. 379-383. doi: $10.5006 / 1.3315948$

[13] F. L. Fragata, C. R. S. Mussoi, C. F. Moulin, I. C. P. Margarit and O. R. Mattos, "Influence of Extender Pigments on the Performance of Ethyl Silicate Zinc-Rich Paints," Journal of Coating Technology, Vol. 65, No. 816, 1993, pp. 103-109.

[14] S. Feliu, R. Barajas, J. M. Bastidas, M. Morcillo and S. Feliu, "Electrochemical Impedance; Analysis and Interpretation, ASTM STP 1188," In: J. R. Scully, D. C. Silverman and M. W. Kendig, Eds., American Society for Testing and Materials, American Technical Publishers Ltd., Philadelphia, 1993, p. 438. doi:10.1520/STP18084S

[15] S. G. Real, A. C. Elias, J. R. Vilche, C. A. Gervasi and A. R. D. Sarli, "An Electrochemical Impedance Spectroscopy Study of Zinc-Rich Paint," Electrochimica Acta, Vol. 38, No. 14, 1993, pp. 2029-2035. doi:10.1016/0013-4686(93)80336-X

[16] C. A. Gervasi, A. R. D. Sarli, E. Cavalcanti, O. Ferraz, E. C. Bucharsky, S. G. Real and J. R. Vilche, "The Corrosion Protection of Steel in Sea Water Using Zinc-Rich Alkyd Paints, an Assesment of the Pigment -Content Effect by EIS," Corrosion Science, Vol. 36, No. 17, 1994, pp. 1963-1972. doi:10.1016/0010-938X(94)90002-7

[17] C. M. Abreu, M. Izquierdo, P. Merino, X. R. Novoa and C. Perez, "A New Approach to the Determination of the Cathodic Protection Period in Zinc-Rich Paints," Corrosion, Vol. 55, No. 12, 1999, p. 1173. doi: $10.5006 / 1.3283955$

[18] S. Feliu, Jr., M. Morcillo and S. Feliu, "Deterioration of Cathodic Protection Action of Zinc-Rich Paint Coatings in Atmospheric Exposure," Corrosion, Vol. 57, No. 7, 2001, pp. 591-597. doi:10.5006/1.3290386

[19] J. R. Vilche, E. C. Bucharsky and C. A. Giudice, "Application of EIS and SEM to Evaluate the Influence of Pigment Shape and Content in ZRP Formulations on the
Corrosion Prevention of Naval Steel," Corrosion Science, Vol. 44, No. 44, 2002, pp. 1287-1309. doi:10.1016/S0010-938X(01)00144-5

[20] C. M. Abreu, L. Espada, M. Izquierdo, P. Merino and X. R. Novoa, "Zinc Rich Powder Coatings in Sea Water," In: Fedrizzi and Bonora Ed., Eurocorr'96, Acropolis, NiceFrance, Vol. 20, 1997, p. 23.

[21] F. Mansfeld, J. B. Lumsden, S. L. Jeanjaquet and S. Tsaï, "Evaluation of Surface Pretreatment Methods for Application of Organic Coatings," Corrosion Control by Organic Coatings, 1981, pp. 227-237.

[22] X. R. Novoa, M. Izquierdo, P. Merino and L. Espada, "Electrochemical Impedance Spectroscopy and Zero Resistance Ammetres (ZRA) as Tools for Studying the Behaviour of Zinc-Rich Inorganic Coatings," Material Science Forum, Vol. 44-45, 1989, pp. 223-234. doi:10.4028/www.scientific.net/MSF.44-45.223

[23] K. Belmokre, N Azzouz, F. Kermiche, M. Wery and J. Pagetti, "Corrosion Study of Carbon Steel Used by Sonatrach International Society, Protected by a Primer by Electrochemical Impedance Spectroscopy in a Deaerated Simulated Soil," Materials Science Forum, Vol. 289-292, 1998, pp. 359-371. doi:10.4028/www.scientific.net/MSF.289-292.359

[24] J. M. Genin, D. Rezel, P. Bauer and A. O. Beral, "Electrochemistry Methods in Corrosion Research, Vol. 8, 1986, pp. 477-490.

[25] H. J. A. Breur, G. M. Ferrari, J. van Turnhout and J. H. W. de Wit, "Modern Experimental Techniques for the Assessment of the Water Sensivity of Organic Coatings," Symposium New trends in Organic Coatings for Marine Environments, Lisbon, 22-24 July 1998, pp.1-8.

[26] F. Deflorian, L. Fedrizzi, D. Lenti and P. L. Bonora, "On the Corrosion Protection Properties of Fluoropolymer Coatings," Progress in Organic Coatings, Vol. 22, No. 1-4, 1993, pp. 39-53. doi:10.1016/0033-0655(93)80014-2

[27] C. Lin, T. Nguyen and M. McKnight, "Relation between AC Impedance Data and Degradation of Coated Steel. I: Effects of Surface Roughness and Contamination on the Corrosion Behavior of Epoxy-Coated Steel," Progress in Organic Coatings, Vol. 20, No. 2, 1992, pp. 169-186.

[28] H. Marchebois, C. Savall, J. Bernard and S. Touzain, "Electrochemical Behavior of Zinc-Rich Powder in Artificial Sea Water," Electrochimica Acta, Vol. 49, No. 17-18, 2004, pp. 2945-2959.

[29] G. Grundmeier, W. Schmidt and M. Stratmann, "Corrosion Protection by Organic Coatings: Electrochemical Mechanism and Novel Methods of Investigation," Electrochimica Acta, Vol. 45, No. 15-16, 2000, pp. 25152533. doi:10.1016/S0013-4686(00)00348-0

[30] A. Meroufel and S. Touzain, "EIS Characterisation of New Zinc-Rich Powder Coatings," Progress in Organic Coatings, Vol. 59, No. 3, 2007, pp. 197-205. doi:10.1016/j.porgcoat.2006.09.005

[31] C. M. Abreu, M. Izquierdo, M. Keddam, X. R. Novoa and H. Takenouti, "Elechtrochemical Behaviour of ZincRich Epoxy Paints in 3\% NaCl Solution," Electrochimica Acta, Vol. 41, No. 15, 1996, pp. 2405-2415. 


$$
\text { doi:10.1016/0013-4686(96)00021-7 }
$$

[32] S. Feliu Jr., R. Barajas, J. M. Bastidas, M. Morcillo and S. Feliu, "Study of Protection Mechanisms of Zinc-Rich Paints by Electrochemical Impedance Spectroscopy," In: Electrochemical Impedance: Analysis and Interpretation, 1993, pp. 438-449.

[33] V. B. Miskovic-Stankovic, J. B. Zotovic, Z. Kacarevic-Popovic and M. D. Maksimovic, "Corrosion Behaviour of Epoxy Coatings Electrodeposited on Steel Electrochemically Modified by Zn-Ni Alloy," Electrochimica Acta, Vol. 44, No. 24, 1999, pp. 4269-4277. doi:10.1016/S0013-4686(99)00142-5

[34] Q. L. Thu, H. Takenouti and S. Touzain, "EIS Characterization of Thick Flawed Organic Coatings Aged Under Cathodic Protection in Sea Water," Electrochimica Acta, Vol. 51, No. 12, 2006, pp. 2491-2502. doi:10.1016/i.electacta.2005.07.049

[35] M. Tzolov, N. Tzenov, D. Dimova-Malinovska, M. Kalitzova, C. Pizzuto, G. Vitali, G. Zollo and I. Ivanov, "Vibrational Properties and Structure of Undoped and Al-Doped ZnO Films Deposited by RF Magnetron Sput- tering," Thin Solid Films, Vol. 379, No. 1-2, 2000, pp. 28-36. doi:10.1016/S0040-6090(00)01413-9

[36] C. Cachet, et al., "EIS Investigation of Zinc Dissolution in Aerated Sulphate Medium. Part II: Zinc Coatings," Electrochimica Acta, Vol. 47, No. 21, 2002, pp. 34093422. doi:10.1016/S0013-4686(02)00277-3

[37] V. Ligier, M. Wéry, J. Y. Hihn, J. Faucheu and M. Tachez, "Formation of Main Atmospheric Zinc and Products: $\mathrm{NaZn}_{4} \mathrm{Cl}(\mathrm{OH})_{6} \mathrm{SO}_{4} \cdot 6 \mathrm{H}_{2} \mathrm{O}, \mathrm{Zn}_{4} \mathrm{SO}_{4}(\mathrm{OH})_{6} \cdot \mathrm{nH}_{2} \mathrm{O}$ and $\mathrm{Zn}_{4} \mathrm{Cl}_{2}(\mathrm{OH})_{4} \mathrm{SO}_{4} \cdot 5 \mathrm{H}_{2} \mathrm{O}$ in $\left[\mathrm{Cl}^{-}\right]\left[\mathrm{SO}_{4}{ }^{2-}\right]\left[\mathrm{HCO}_{3}^{-}\right]\left[\mathrm{H}_{2} \mathrm{O}_{2}\right]$ Electrolytes," Corrosion Science, Vol. 41, No. 6, 1999, pp. 1139-1164. doi:10.1016/S0010-938X(98)00176-0

[38] A. Kalendová, “Alkalising and Neutralising Effects of Anticorrosive Pigments Containing $\mathrm{Zn} \mathrm{Mg}, \mathrm{Ca}$ and $\mathrm{Sr}$ Cations," Progress in Organic Coating, Vol. 38, No. 3-4, 2000, pp. 199-206. doi:10.1016/S0300-9440(00)00103-X

[39] P. Kalenda, "Effects of Particle Sizes and Shapes of Zinc Metal on the Properties of Anticorrosive Coatings," Progress in Organic Coatings, Vol. 46, No. 4, 1993, pp. 324 332. 